\title{
Saccharophagus degradans gen. nov., sp. nov., a versatile marine degrader of complex polysaccharides
}

\author{
Nathan A. Ekborg, ${ }^{1}$ Jose M. Gonzalez, ${ }^{2}$ Michael B. Howard, ${ }^{1}$ \\ Larry E. Taylor, ${ }^{3}$ Steven W. Hutcheson ${ }^{1}$ and Ronald M. Weiner ${ }^{1}$ \\ ${ }^{1}$ Department of Cell Biology and Molecular Genetics, University of Maryland, College Park, \\ MD 20742, USA \\ ${ }^{2}$ Department of Microbiology and Cell Biology, University of La Laguna, 38206 La Laguna, \\ Tenerife, Spain \\ ${ }^{3}$ Department of Marine Estuarine Environmental Sciences, College Park, MD 20742, USA
}

\begin{abstract}
Gammaproteobacteria belonging and related to the genus Microbulbifer are an emerging group of complex carbohydrate-degrading marine bacteria. Previously, all of the representatives were placed within Microbulbifer or were unclassified. Recently, a new genus, Teredinibacter, represented by a single species, Teredinibacter turnerae, was formed to include an endosymbiotic branch of these organisms. In this study, based on 16S rRNA gene sequence similarity and phenotypic analyses, a new genus, Saccharophagus, is proposed to accommodate the most versatile marine carbohydrate degrader yet identified, Saccharophagus degradans gen. nov., sp. nov. $2-40^{\top}$ (=ATCC $43961^{\top}=$ DSM $\left.17024^{\top}\right)$. S. degradans strain $2-40^{\top}$ can degrade 10 tested complex polysaccharides: agar, alginate, chitin, cellulose, fucoidan, laminarin, pectin, pullulan, starch and xylan. S. degradans $2-40^{\top}$ shares $90.5 \% 16 S$ rRNA gene sequence similarity with the type strain of the Microbulbifer type species, Microbulbifer hydrolyticus IRE- $31^{\top}$, and $91.5 \%$ with T. turnerae $T 7902^{\top}$, and can be further distinguished from members of these two genera by $16 \mathrm{~S}$ rRNA gene cluster analysis, the ability to utilize 10 different complex polysaccharides as sole carbon sources, a significantly lower $G+C$ content and differences in fatty acid content. The three genera of complex polysaccharide-degrading, marine bacteria now encompass 20 strains from diverse marine niches.
\end{abstract}

The carbon cycle in marine habitats has not yet been elucidated, as many of the micro-organisms that degrade complex polysaccharides (CPs), especially those derived from higher plants and algae, have not been identified. These include highly specialized micro-organisms that recycle $\mathrm{CP}$, a critical step in the marine food web. Within the past decade a number of such bacteria have been discovered.

In 1997, a Gram-negative bacterium that degrades cellulose, xylan and chitin was isolated by Gonzalez et al. (1997) from a salt marsh in Georgia, USA, and named Microbulbifer hydrolyticus IRE-31 ${ }^{\mathrm{T}}$. In 2002, Distel et al. (2002) reported taxonomic criteria for a shipworm symbiont that degrades cellulose and found them to be sufficiently different from

Published online ahead of print on 4 March 2005 as DOI 10.1099/ ijs.0.63627-0.

Abbreviation: $\mathrm{CP}$, complex polysaccharide.

The GenBank/EMBL/DDBJ accession number for the $16 \mathrm{~S}$ rRNA gene sequence of strain $2-40^{\top}$ is AF055269. the Microbulbifer taxon to be accorded a new genus, Teredinibacter. Within the past 2 years, sequences from six strains related to Microbulbifer have been deposited in the GenBank database.

In 1986, Andrykovitch \& Marx (1988) isolated bacteria involved in the degradation of a salt marsh grass, Spartina alterniflora, found in the lower Chesapeake Bay, USA. One of these was designated strain $2-40^{\mathrm{T}}$. Based upon phenotypic characteristics, it was placed with the alteromonads, where it resides today in the order 'Alteromonadales' of the 'Gammaproteobacteria', in the family Alteromonadaceae. Later, based on sequence analysis of the 16S rRNA gene, its distinctive cellular morphology and its $\mathrm{CP}$-degradative capabilities, $2-40^{\mathrm{T}}$ was considered to be closely related to the genus Microbulbifer. A more meaningful classification of strain $2-40^{\mathrm{T}}$ had been hampered by the limited availability of $16 \mathrm{~S}$ rRNA gene sequences from closely related organisms. Now, on the basis of more than 20 available sequences, we propose a new genus, Saccharophagus, to accommodate the most versatile marine carbohydrate degrader yet identified. 
Strain $2-40^{\mathrm{T}}$ can degrade at least 10 CPs: agar, alginate, chitin, cellulose, fucoidan, laminarin, pectin, pullulan, starch and xylan (Ensor et al., 1999; Howard et al., 2003). These CPs are derived from numerous sources including algae, land plants, crustaceans, bacteria and fungi. Because of its involvement in ocean and estuarine carbon cycles, the US Department of Energy has recently (February 2005) completed sequencing the genome of strain $2-40^{\mathrm{T}}$ (http:// genome.jgi-psf.org/draft_microbes/micde/micde.home.html; named as 'Microbulbifer degradans'). Genomic analysis has predicted that there are $>130$ open reading frames that encode enzymes involved in the depolymerization of CPs. Additionally, it is likely that at least another 100-200 genes are involved in signalling, regulation and further metabolism of CPs.

Strain $2-40^{\mathrm{T}}$ clusters with the marine CP-degrading genera. Its $16 \mathrm{~S}$ rRNA gene sequence is most closely related to those of M. hydrolyticus $(90.5 \%)$ and Teredinibacter turnerae $(91 \cdot 5 \%)$; it shares the ability to degrade CPs with both $M$. hydrolyticus and T. turnerae and it has similar cellular morphology to that of M. hydrolyticus, most notably the copious production of membrane blebs and vesicles when grown with a $\mathrm{CP}$ as the sole carbon source (Gonzalez \& Weiner, 2000) (Fig. 1). It is proposed that these organisms form a cluster of Gram-negative marine gammaproteobacteria with the ability to degrade CPs. The question remained whether strain $2-40^{\mathrm{T}}$ is sufficiently different from members of these genera to warrant its placement in a new genus.

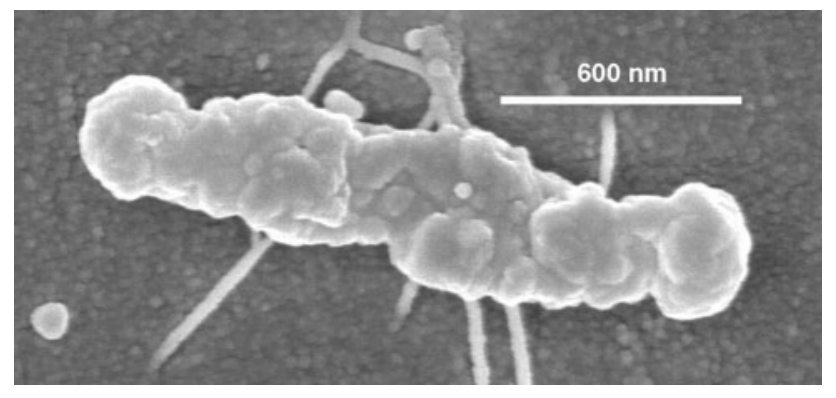

Fig. 1. Scanning electron micrograph of a late stationary phase cell of strain $2-40^{\top}$ grown on glucose as the sole carbon source, viewed at $50000 \times$ magnification. Cells were washed in PBS, fixed in $2 \%$ glutaraldehyde, collected on $0.2 \mu \mathrm{m}$ filters and post-fixed in $2 \% \mathrm{OsO}_{4}$. Following dehydration in a standard ethanol series, the samples were critical-point-dried in $\mathrm{CO}_{2}$, mounted on SEM stubs and coated with gold-palladium alloy to a final thickness of approximately $15 \mathrm{~nm}$ and viewed on a Hitachi S-4700 UltraHigh Resolution scanning electron microscope. Note the irregular surface topology, typical of growth on $\mathrm{CP}$ and in late phases of growth on glucose. Bipolar nodes, fibrils and surface protuberances, some spherical and others irregular in shape, are present. Bar, $600 \mathrm{~nm}$. By contrast, a cell growing exponentially in glucose marine medium has a typical bacillus morphology $(0.8 \times 2.0 \mu \mathrm{m})$ with a smooth surface and a single polar flagellum (Gonzalez \& Weiner, 2000; not shown).
Since the initial report of strain $2-40^{\mathrm{T}}$ (Gonzalez \& Weiner, 2000), 18 additional 16S rRNA gene sequences of related organisms have become available in GenBank. These permitted clarification of the phylogenetic position of strain $2-40^{\mathrm{T}}$ when considered along with available phenotypic analyses. The $16 \mathrm{~S}$ rRNA gene sequence of strain $2-40^{\mathrm{T}}$ was obtained from GenBank (accession no. AF055269). The $16 \mathrm{~S}$ rRNA gene tree (Fig. 2) was generated using CLUSTAL W 1.82 (Chenna et al., 2003) for sequence alignment and the neighbour-joining program in the PHYLIP package (Felsenstein, 1988). Before analysis, a filter was applied to exclude positions with less than $50 \%$ conservation within the sequences being aligned. Only positions 110-1265 (Escherichia coli numbering) were considered. All additional sequences were obtained from the GenBank database. It should also be noted that a metagenomic study of Sargasso Sea prokaryotes revealed putative proteins attributed to isolate Microbulbifer SAR-1 (http://www.ncbi.nlm.nih.gov/ Web/Newsltr/Spring04/sargasso.html). However, 16S rRNA gene sequences from the Sargasso Sea shared $<90 \%$ similarity with any isolate included in Fig. 2 and so are not included in the proposed Microbulbifer/Teredinibacter/ Saccharophagus group.

The inferred position of strain $2-40^{\mathrm{T}}$ falls outside of two branches of the tree (Fig. 2). The first is a Microbulbifer

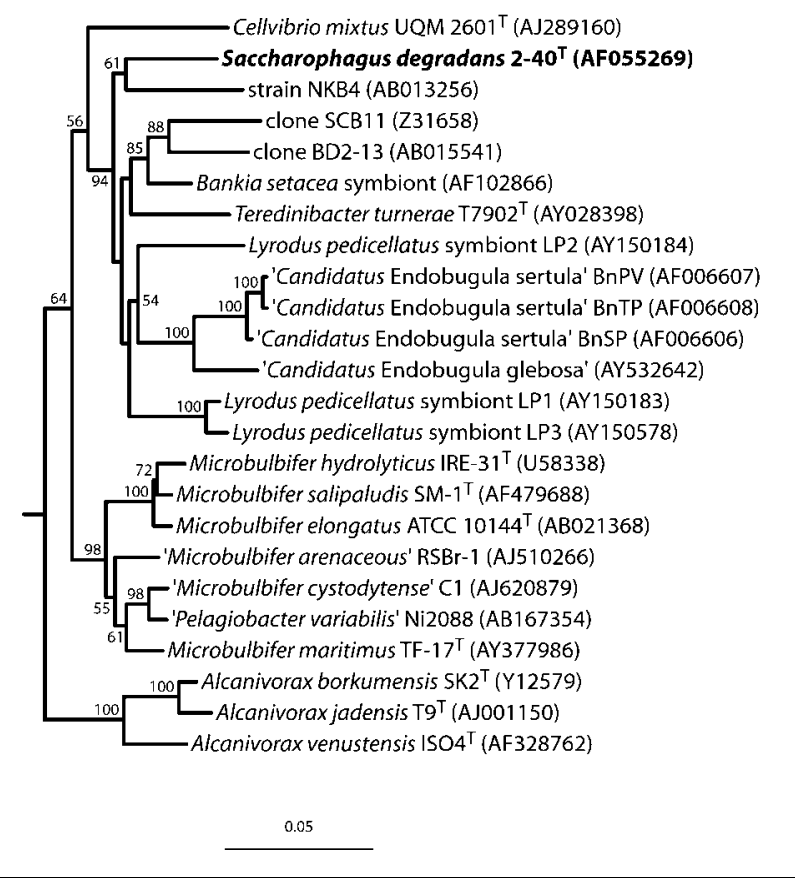

Fig. 2. Phylogenetic position of strain $2-40^{\top}$ based on its $16 \mathrm{~S}$ rRNA gene sequence. The tree was generated using CLUSTAL W 1.82 (Chenna et al., 2003) for sequence alignment and the neighbour-joining program in the PHYLIP package (Felsenstein, 1988). Burkholderia cepacia served as the outgroup (not shown). Numbers at nodes indicate percentage bootstrap values above 50 (100 replicates). Bar, Jukes-Cantor evolutionary distance of 0.05 . 
cluster that contains seven members, including 'Pelagiobacter variabilis' (Imamura et al., 1997). This cluster is supported by a high bootstrap score. Six members were isolated from aquatic marine habitats, while 'Microbulbifer arenaceous' was isolated within coastal sandstone (Tanaka et al., 2003). The type species of the genus Microbulbifer is M. hydrolyticus (type strain IRE- $31^{\mathrm{T}}$ ).

The second branch is more diffuse and contains organisms from diverse marine niches, predominantly endosymbionts. Only one of these, T. turnerae, has been given a validly published name (Distel et al., 2002). T. turnerae, LP1, LP2, LP3 and AF102866 are endosymbionts of shipworms from the bivalve family Teredinidae, while 'Candidatus Endobugula glebosa' and 'Candidatus Endobugula sertula' were isolated from the pallial sinuses of the bivalve Bugula neritina (Haygood \& Davidson, 1997; Lim \& Haygood, 2004). Strain NKB4 was isolated from deep-sea sediments (Li et al., 1999b). The 16S rRNA gene sequences of strains SCB11 and BD2-13 were derived gene clones from marine environmental samples (Li et al., 1999a). Strain characteristics for these organisms have not been reported.

Strain $2-40^{\mathrm{T}}$ shares a maximum of $91 \%$ 16S rRNA gene sequence similarity with members of the genus Microbulbifer and $93 \%$ similarity with the endosymbiont cluster. It shares 91.9 and $91.3 \%$ similarity with BD2-13 and SCB11, respectively. These data suggest that strain $2-40^{\mathrm{T}}$ is related to the other members included in the $16 \mathrm{~S}$ rRNA gene tree, but below the species level. This is in agreement with previously published data (Distel et al., 2002; Gonzalez \& Weiner, 2000; Tanaka et al., 2003; Yoon et al., 2003a).

The suggestion that strain $2-40^{\mathrm{T}}$ is distinct from the other Microbulbifer/Teredinibacter isolates is also supported by comparison of phenotypic characteristics (Table 1). Most notably, the $\mathrm{G}+\mathrm{C}$ content of strain $2-40^{\mathrm{T}}$ is significantly lower than that estimated for the other organisms, $46.7 \mathrm{~mol} \%$ as reported by Gonzalez \& Weiner (2000) and $45.8 \mathrm{~mol} \%$ as determined from the draft genomic sequence, compared with $57 \cdot 7 \mathrm{~mol} \%$ for M. hydrolyticus and $49-$ $51 \mathrm{~mol} \%$ for several T. turnerae strains (Distel et al., 2002). Furthermore, the major fatty acid of strain $2-40^{\mathrm{T}}$ is iso- $\mathrm{C}_{16: 0}$ $(37 \%)$ (Gonzalez \& Weiner, 2000), while iso- $\mathrm{C}_{15: 0}$ is the primary fatty acid of M. hydrolyticus (Gonzalez et al., 1997) and Microbulbifer salipaludis (Yoon et al., 2003a). Strain $2-40^{\mathrm{T}}$ reduces nitrate to nitrite and synthesizes eumelanin via tyrosinase activity (Kelly et al., 1990), both traits reported for only one other strain, ' $M$. arenaceous' (Tanaka et al., 2003), which does not degrade agar and shares only $90 \cdot 6 \% 16 \mathrm{~S}$ rRNA gene sequence similarity with strain $2-40^{\mathrm{T}}$.

Strain $2-40^{\mathrm{T}}$ was known to degrade at least $10 \mathrm{CPs}$, many more than had been reported for T. turnerae and strains of Microbulbifer (Table 1). However, because this required additional confirmation, the differences in CP-degradative capabilities within the Microbulbifer/Teredinibacter/ Saccharophagus group of bacteria were investigated.

Table 1. Distinguishing characteristics of strain $2-40^{\top}$ compared with Microbulbifer species and T. turnerae

Species/strains: 1, strain 2-40 ${ }^{\mathrm{T}}$ [data from Gonzalez \& Weiner (2000) unless indicated]; 2, M. hydrolyticus (Gonzalez et al., 1997); 3, M. salipaludis (Yoon et al., 2003a); 4, M. elongatus (Yoon et al., 2003b); 5, Microbulbifer maritimus (Yoon et al., 2004); 6, 'M. arenaceous' (Tanaka et al., 2003); 7, T. turnerae (Distel et al., 2002). Substrates were tested for depolymerization and utilization; +, substrate depolymerized; - , substrate not depolymerized under conditions tested. ND, Not described.

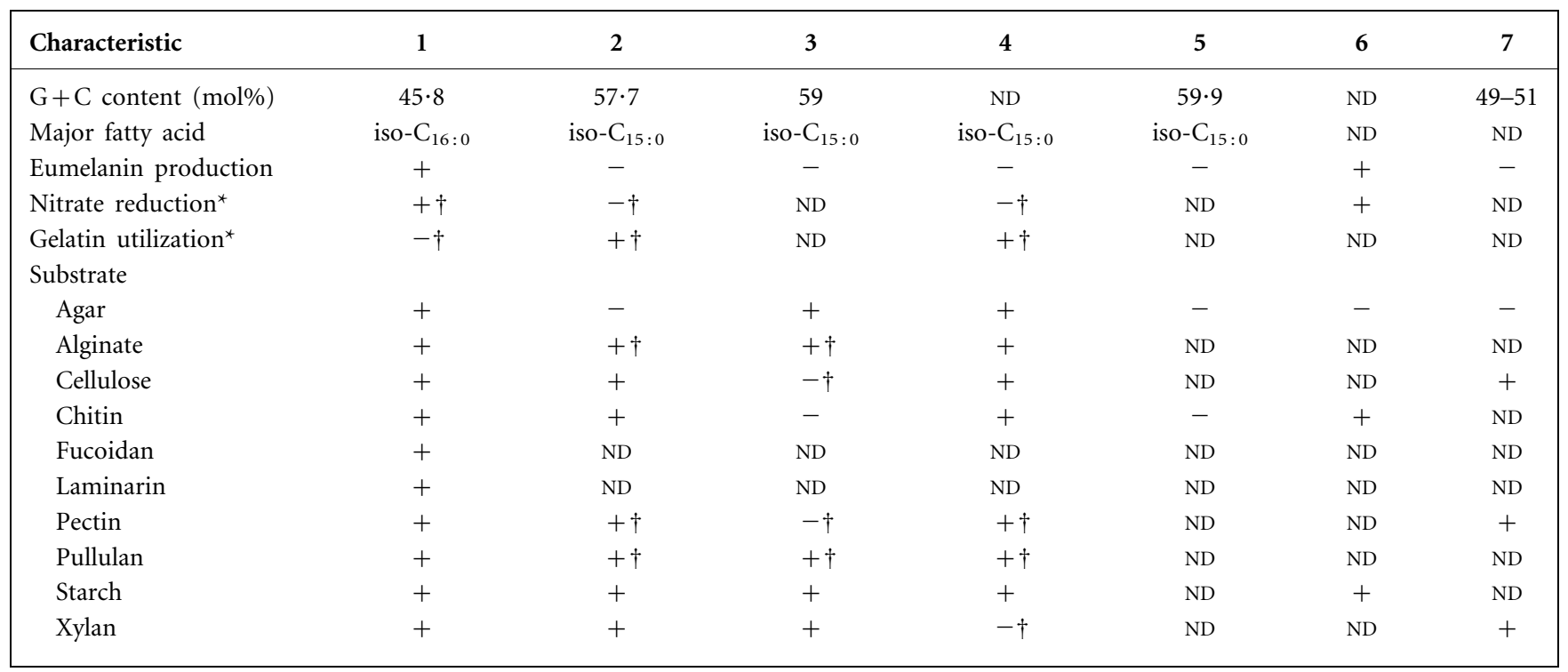

${ }^{*}$ Using API 20NE test strips.

$\dagger$ Determined in this study. 
M. hydrolyticus, Microbulbifer elongatus and M. salipaludis were tested for their abilities to degrade alginate, cellulose, pectin, pullulan and xylan compared with strain $2-40^{\mathrm{T}}$.

Assays for the depolymerization of cellulose, pullulan and xylan utilized azurine-cross-linked polysaccharides (Megazyme; http://www.megazyme.com/) incorporated into $1 / 3$ strength marine agar (Difco 2216). Degradation of these insoluble substrates by endohydrolases produced soluble dye-labelled fragments that were easily observed as blue haloes around active colonies. M. hydrolyticus was used as a positive control for xylan and cellulose utilization. Gelatin utilization and nitrate reduction were determined by API $20 \mathrm{NE}$ test strips supplemented with sea salts medium $(2 \cdot 3 \%$ sea salts, $0 \cdot 05 \%$ yeast extract).

To assay for growth on alginate or pectin, strains were grown in minimal sea salts liquid medium incorporating the polysaccharide of interest $(0 \cdot 2 \%$ final concentration). The disappearance of the polysaccharides and a reduction of broth viscosities indicated the degradation of alginate and pectin. Negative controls included media without polysaccharide. Strain $2-40^{\mathrm{T}}$ was used as a positive control. The results are summarized in Table 1 .

Strain $2-40^{\mathrm{T}}$ depolymerized all the tested substrates shown. Each of the other related strains was negative for at least one of the substrates, even considering the fact that not every strain was available. The versatility of strain $2-40^{\mathrm{T}} \mathrm{CP}$ degradation is unique among the other strains of the Microbulbifer/Teredinibacter/Saccharophagus group and even among any other known bacteria. We believe that the phylogenetic and phenotypic analyses presented here, together with other published recommendations (Distel et al., 2002; Solano \& Sanchez-Amat, 1999), support the classification of strain $2-40^{\mathrm{T}}$ as the type strain of Saccharophagus degradans gen. nov., sp. nov.

\section{Description of Saccharophagus gen. nov.}

Saccharophagus (Sac' cha.ro.pha'gus. Gr. n. saccharon sugar; N.L. masc. n. phagus from Gr. masc. n. phagos glutton; N.L. masc. n. Saccharophagus sugar-devourer).

Gram-negative, motile, heterotrophic, pleomorphic, rodshaped, aerobic, catalase-positive and oxidase-positive. Numerous cell surface blebs and vesicles are produced. Degrades numerous complex polysaccharides. Requires sea salts for growth. The type species is Saccharophagus degradans.

\section{Description of Saccharophagus degradans sp. nov.}

Saccharophagus degradans (de.gra'dans L. part. adj. degradans bringing back into the former order, used to refer to the ability of the type strain to degrade several complex carbohydrates).

Cells are pleomorphic rods, averaging $1 \cdot 5-3 \cdot 0 \mu \mathrm{m}$ long and
$0.5 \mu \mathrm{m}$ wide during the exponential phase of growth in glucose. In media containing complex polysaccharides as sole carbon sources, cells can be pleomorphic and produce surface protuberances and vesicles. Cells form coils and filaments when grown at high salinity. Colonies are cream in colour and then turn black upon eumelanin production. Colonies rapidly pit agar plates. Capable of utilizing the following complex carbohydrates as sole carbon sources: agar, alginate, chitin, cellulose, fucoidan, laminarin, pectin, pullulan, starch and xylan. Hydrolyses tyrosine. Temperature range for growth is $4-37^{\circ} \mathrm{C}$ with an optimum of $30^{\circ} \mathrm{C}$. Optimum $\mathrm{pH}$ for growth is $7 \cdot 5$ with a range of $4 \cdot 5-10$. Requires sea salts for growth in the range $1-10 \%$ with an optimum of $3.5 \%$. Secretes proteases. The $\mathrm{G}+\mathrm{C}$ content of the type strain is $45 \cdot 8 \mathrm{~mol} \%$ as determined by genomic sequencing.

The type strain (and only strain to date) is $2-40^{\mathrm{T}}$ (=ATCC $43961^{\mathrm{T}}=$ DSM $\left.17024^{\mathrm{T}}\right)$. It was isolated from the surface of degrading salt marsh cord grass, Spartina alterniflora, in the lower Chesapeake Bay, Mathews County, VA, USA.

\section{Acknowledgements}

This work was funded by grants from the National Science Foundation (DEB0109869), the Maryland Sea Grant College (SA7528051E), the US-Israel Binational Fund (BSF) and Tedco. We thank Ilya Borovok, TAU, and Dan Distal, OGL, for their suggestions.

\section{References}

Andrykovitch, G. \& Marx, I. (1988). Isolation of a new polysaccharide-digesting bacterium from a salt marsh. Appl Environ Microbiol 54, 1061-1062.

Chenna, R., Sugawara, H., Koike, T., Lopez, R., Gibson, T. J., Higgins, D. G. \& Thompson, J. D. (2003). Multiple sequence alignment with the CLUSTAL series of programs. Nucleic Acids Res 31, 3497-3500

Distel, D. L., Morrill, W., MacLaren-Toussaint, N., Franks, D. \& Waterbury, J. (2002). Teredinibacter turnerae gen. nov., sp. nov., a dinitrogen-fixing, cellulolytic, endosymbiotic $\gamma$-proteobacterium isolated from the gills of wood-boring molluscs (Bivalvia: Teredinidae). Int J Syst Evol Microbiol 52, 2261-2269.

Ensor, L., Stosz, S. \& Weiner, R. (1999). Expression of multiple complex polysaccharide-degrading enzyme systems by marine bacterium strain 2-40. J Ind Microbiol Biotechnol 23, 123-126.

Felsenstein, J. (1988). Phylogenies from molecular sequences: inference and reliability. Annu Rev Genet 22, 521-565.

Gonzalez, J. M. \& Weiner, R. M. (2000). Phylogenetic characterization of marine bacterium strain 2-40, a degrader of complex polysaccharides. Int J Syst Evol Microbiol 50, 831-834.

Gonzalez, J. M., Mayer, F., Moran, M. A., Hodson, R. E. \& Whitman, W. B. (1997). Microbulbifer hydrolyticus gen. nov., sp. nov., and Marinobacterium georgiense gen. nov., sp. nov., two marine bacteria from a lignin-rich pulp mill waste enrichment community. Int J Syst Bacteriol 47, 369-376.

Haygood, M. G. \& Davidson, S. K. (1997). Small-subunit rRNA genes and in situ hybridization with oligonucleotides specific for the bacterial symbionts in the larvae of the bryozoan Bugula neritina and 
proposal of "Candidatus Endobugula sertula". Appl Environ Microbiol 63, 4612-4616.

Howard, M. B., Ekborg, N. A., Taylor, L. E., Weiner, R. M. \& Hutcheson, S. W. (2003). Genomic analysis and initial characterization of the chitinolytic system of Microbulbifer degradans strain 2-40. J Bacteriol 185, 3352-3360.

Imamura, N., Nishijima, M., Takadera, T., Adachi, K., Sakai, M. \& Sano, H. (1997). New anticancer antibiotics pelagiomicins, produced by a new marine bacterium Pelagiobacter variabilis. J Antibiot 50, $8-12$.

Kelly, S., Coyne, V., Sledjeski, D., Fuqua, W. \& Weiner, R. (1990). Identification of a tyrosinase from a periphytic marine bacterium. FEMS Microbiol Lett 67, 275-280.

Li, L., Kato, C. \& Horikoshi, K. (1999a). Bacterial diversity in deep-sea sediments from different depths. Biodivers Conserv 8, 659-677.

Li, L., Guezennec, J., Nichols, P., Henry, P., Yanagibayashi, M. \& Kato, C. (1999b). Microbial diversity in Nankai Trough sediments at a depth of 3,843 m. J Oceanogr 55, 635-642.
Lim, G. E. \& Haygood, M. G. (2004). "Candidatus Endobugula glebosa," a specific bacterial symbiont of the marine bryozoan Bugula simplex. Appl Environ Microbiol 70, 4921-4929.

Solano, F. \& Sanchez-Amat, A. (1999). Studies on the phylogenetic relationships of melanogenic marine bacteria: proposal of Marinomonas mediterranea sp. nov. Int J Syst Bacteriol 49, 1241-1246.

Tanaka, T., Yan, L. \& Burgess, J. G. (2003). Microbulbifer arenaceous sp. nov., a new endolithic bacterium isolated from the inside of red sandstone. Curr Microbiol 47, 412-416.

Yoon, J. H., Kim, I. G., Shin, D. Y., Kang, K. H. \& Park, Y. H. (2003a). Microbulbifer salipaludis sp. nov., a moderate halophile isolated from a Korean salt marsh. Int J Syst Evol Microbiol 53, 53-57.

Yoon, J. H., Kim, H., Kang, K. H., Oh, T. K. \& Park, Y. H. (2003b). Transfer of Pseudomonas elongata Humm 1946 to the genus Microbulbifer as Microbulbifer elongatus comb. nov. Int J Syst Evol Microbiol 53, 1357-1361.

Yoon, J. H., Kim, I. G., Oh, T. K. \& Park, Y. H. (2004). Microbulbifer maritimus sp. nov., isolated from an intertidal sediment from the Yellow Sea, Korea. Int J Syst Evol Microbiol 54, 1111-1116. 